\title{
Task-Based Language Teaching and English for Academic Purposes: An Investigation into Instructor Perceptions and Practice in the Canadian Context
}

\author{
Scott Roy Douglas E Marcia Kim
}

English for Academic Purposes (EAP) programs designed to meet postsecondary English language proficiency requirements are a common pathway to higher education for students from non-English-speaking backgrounds. Grounded in a Canadian context, this study seeks to examine the prevalence of Task-Based Language Teaching (TBLT) in EAP, common examples of EAP tasks, and the benefits and drawbacks of this approach for EAP students. EAP professionals $(\mathrm{n}=42)$ were recruited from the membership of TESL Canada, and participants completed a questionnaire on their perceptions of TBLT for EAP. Of those who participated, $69 \%$ reported using TBLT in at least half of their lessons, with $86 \%$ of the participants indicating that TBLT was suitable for EAP instruction. Further qualitative analysis of the data revealed that presentations, essays, and interviews were the top three tasks employed by EAP teachers; the practicality, effectiveness, and learner-centredness of TBLT were its major benefits; and mismatched student expectations, lack of classroom time, and excessive instructor preparation were TBLT's major drawbacks. Ambiguity regarding what constitutes TBLT was also found in the data. It appears that TBLT is used by participants across Canada and is well accepted as a teaching approach. However, some concerns associated with TBLT in EAP remain to be addressed.

Les programmes d'anglais académique visant à combler les exigences en matière de compétences linguistiques pour l'anglais au postsecondaire représentent souvent une voie vers les études postsecondaires pour les élèves allophones. Située dans un contexte canadien, cette étude porte sur la prévalence de l'enseignement des langues basé sur les tâches (ELBT) dans les cours d'anglais académique, des exemples courants de tâches dans ces cours, et les avantages et les inconvénients de cette approche pour les élèves. À partir des membres de TESL Canada, on a recruté des enseignants d'anglais académique $(\mathrm{n}=42)$ et ceux-ci ont complété un questionnaire portant sur leurs perceptions de l'ELBT dans les cours d'anglais académique. Les résultats indiquent que 69\% des participants emploient l'ELBT dans au moins la moitié de leurs leçons et que 86\% jugent l'ELBT approprié pour l'enseignement de l'anglais académique. Une analyse quantitative plus poussée 
a révélé que les trois tâches les plus fréquemment employées par les enseignants d'anglais académique étaient les présentations, les rédactions et les entrevues. De plus, les participants ont indiqué qu'ils estimaient que les atouts principaux de l'ELBT étaient son aspect pratique, son efficacité et le fait qu'il est centré sur l'apprenant; comme inconvénients majeurs, ils ont noté une inadéquation des attentes de la part des étudiants, l'insuffisance des heures de cours et la formation excessive des enseignants. Les données ont également révélé une ambigüité par rapport à ce qui constitue l'ELBT. Il parait que l'ELBT est employé partout au Canada et est bien accueilli comme méthode enseignement; toutefois, il faudrait aborder certaines préoccupations quant à son emploi dans l'enseignement de l'anglais académique.

Over the past 10 years, increasing numbers of new immigrants and international students from non-English-speaking backgrounds have been seeking admission to English-medium postsecondary institutions in Canada. For example, in the period between 2004 and 2012, there was a 60\% increase in the number of international students studying in Canadian institutions (Citizenship and Immigration Canada, 2013). Some students from non-Englishspeaking backgrounds are able to gain entry to the Canadian system of higher education through high-stakes standardized English language proficiency testing. Others enrol in English for Academic Purposes (EAP) programs designed to fulfill the proficiency requirements for entry into English-medium higher education. Finding alternatives to traditional standardized English language proficiency testing, such as EAP, is a necessary part of promoting access for these students to the same educational opportunities as students from English-speaking backgrounds. However, the effectiveness of EAP pathway programs at times appears to be mixed, with a particular inability of students to transfer the skills garnered in EAP courses to their mainstream university studies (see Baik \& Greig, 2009; Counsell, 2011). A possible solution is the implementation of content-focused task-based teaching that mirrors authentic tasks EAP students will carry out in their mainstream studies. In this approach, the EAP classroom is seen as a natural fit for task-based language teaching (TBLT) because it allows the students to use language and skills in situations they will face in their academic lives (Alexander, Argent, \& Spencer, 2008).

Studies exploring teacher perceptions of the suitability of TBLT have so far been limited mainly to English as a Foreign Language (EFL) contexts. Jeon and Hahn (2006) interviewed Korean secondary school teachers and found that the teachers felt a task-based approach motivated students and was appropriate for group work. McDonough and Chaikitmongkol (2007) interviewed EFL teachers at a university in Thailand who reported that the students became more independent in their learning. The teachers also reported that the students gained academic skills they could use in other 
courses (McDonough \& Chaikitmongkol, 2007). Although these teachers felt positive about TBLT, they expressed concerns about certain features of a task-based approach. The Korean secondary school teachers, for example, felt that assessing task performance was an issue (Jeon \& Hahn, 2006). The teachers in the study felt that assigning the same grade to all students in a group was unfair and that they needed to consider different features of the group work in order to assign a grade (Jeon \& Hahn, 2006). In the McDonough and Chaikitmongkol (2007) study, the teachers were concerned about the "amount or type of grammar instruction" (p. 118) in the taskbased course, and some of the teachers were concerned about the amount of material they had to cover.

While these studies provide insight into teacher perceptions of TBLT in different contexts (Jeon \& Hahn, 2006; McDonough \& Chaikitmongkol, 2007), there have been few studies directly concerned with teachers' perceptions of the effectiveness of TBLT in EAP, particularly in a Canadian context. This article addresses the lack of exploration of TBLT and EAP in the Canadian context by reporting the results of a study that investigated the prevalence of TBLT in Canadian EAP classrooms and how EAP instructors perceived the benefits and drawbacks of this teaching approach. As such, the refined research questions for this research study are as follows:

1. To what extent do EAP instructors report employing TBLT in their EAP classes?

2. From EAP instructors' perspectives, what are successful examples of TBLT used with EAP learners?

3. For EAP instructors, what are the perceived benefits and drawbacks of employing TBLT in their teaching practice?

\section{Background Literature}

\section{What is TBLT?}

TBLT is an approach to language teaching that provides opportunities for students to engage in the authentic use of the target language through tasks. As the principal component in TBLT, the task provides the main context and focus for learning, and it encourages language use similar to the way language is used outside of the classroom. Students learn language and develop skills as they work toward completing the task, which motivates them to stretch their available language resources (Ellis, 2003a).

Differing perspectives and purposes of researchers and teacher educators studying tasks and TBLT have resulted in varied definitions of task in the literature (Samuda \& Bygate, 2008). The following examples illustrate the range of definitions, but are not meant to exhaust the possibilities. Willis (1996) says, "tasks are always activities where the target language is used by the 
learner for a communicative purpose (goal) in order to achieve an outcome" (p. 23). According to Willis, a role-play that includes a team of entrepreneurs arguing a case study to solve a problem is an example of a task because it includes a goal. On the other hand, a role-play in which students are given a role to practice a prescribed grammar item would not be considered a task. Willis's definition suggests a natural use of English. Nunan (2004) expands on Willis's definition by claiming that "a pedagogical task is a piece of classroom work that involves learners in comprehending, manipulating, producing, or interacting in the target language ... and in which the intention is to convey meaning rather than to manipulate form" (p. 4). Like Willis's definition of a classroom task, Nunan's discussion of TBLT agrees that tasks are meaningoriented. Another definition of task (Long \& Crookes, 1992) focuses on things individuals do in the "real world":

[A task is] a piece of work undertaken for oneself or for others, freely or for some reward. Thus, examples of tasks include painting a fence, dressing a child ... In other words, by "task" is meant the hundred and one things people do in everyday life, at work, at play, and in between. (p. 89)

Ellis (2009) narrows Long and Crookes's (1992) wider definition of a task by claiming that a task should meet specific criteria in order to be considered a task. A task has a "primary focus on meaning, a 'gap', which motivates a need to exchange information or give an opinion, and a clearly defined outcome other than the use of language that is reached by the students using their own language resources" (p. 223). The researchers for the current study used Ellis's definition of a task because it emphasizes interaction and negotiating meaning.

\section{Benefits}

The benefits of TBLT have been ably described in the literature. Nunan (2004) emphasizes language use for authentic purposes. For Nunan, TBLT is beneficial because students learn language by communicating interactively while engaging in meaningful tasks. Nunan further feels that TBLT is relevant to students' needs and interests, as it stimulates language learning and skills development necessary for completing tasks that students may encounter outside the classroom. Ellis $(2003 \mathrm{~b}, 2009)$ also underlines these benefits by pointing out that students use self-selected language during tasks, which helps them to focus on the meaning of their message to complete it. Specific language items are not imposed on students, which means they are free of language control. Students use the language that they have rather than practice specified language items.

While the element of being free of overt language control can be perceived as a major benefit of using a task-based approach, TBLT is further beneficial because, as a development of Communicative Language Teaching (CLT), it 
offers a focus both on form and on communication, so it is more effective than approaches that are narrower and do not offer a balance (Larsen-Freeman \& Anderson, 2011). Willis and Willis (2007) describe how the balance in TBLT is evident in the unfolding of a task sequence that involves a focus on language and form contained within the overall emphasis of a focus on meaning. For Willis and Willis, specific vocabulary and grammar can be targeted for study purposes and consciousness-raising. At the beginning of the task sequence, this focus on form involves an examination of language needed for the upcoming task. Language guidance at this stage can be student directed and come from dictionaries, grammar books, or the instructor. However, for Willis and Willis, the most effective position for a focus on form in the task sequence is at the end: the point at which specific language forms are identified to help students make sense of the task experience. Under the instructor's guidance and working in familiar contexts arising from the task, specific vocabulary and grammar, including grammatical explanations, can be isolated for form-focused activities that make sense of the task experience and are useful for future language encounters. Ellis (2003a) further emphasizes that TBLT is flexible enough to fit into different curricula and different teaching contexts. It can also be used to different degrees. Individual tasks can support a course, or tasks can build an entire program. It is an effective approach for teaching all four skills including grammar, pronunciation, and vocabulary (Willis, 1996; Willis \& Willis, 2007).

In addition to being adaptable, task-based language teaching is a studentcentred approach to teaching (Van den Branden, 2012). Students communicate naturally in situations they may experience outside of the classroom with the language that is closely connected to them. In more traditional approaches, the contexts may seem artificial to the students because they were created for language practice and not for the students' needs. In TBLT, the language explored arises from the students' needs, and the students' attention is drawn to form as the task unfolds (Larsen-Freeman \& Anderson, 2011). These needs, and not the teacher or textbook, direct the lesson (Hyland, 2006). Students can feel satisfied that their individual needs are being met and that their opinions or ideas are being heard. TBLT encourages input from students to the teacher about how the learning environment should evolve. Accordingly, it is an active approach to language learning (Larsen-Freeman \& Anderson, 2011) that is highly motivating and improves student confidence (Van den Branden, 2012).

\section{Drawbacks}

TBLT has also been critiqued in the literature. Seedhouse (1999) has shown in studies that there is "a general tendency in TBLT for students to minimize the volume of language used, and to produce only that which is necessary to accomplish the task" (p. 152). In other words, depending on the task and how it has been set up, verbal interactions can be short and simple. It has 
also been postulated that TBLT develops fluency at the expense of accuracy and relies on lexis (Skehan, 1996). Furthermore, Carless (2004) found that students developed strategies to complete tasks quickly, taking shortcuts in their language use and not fully engaging in the learning process. He points out that this problem is related to the design of the tasks which, from the students' perspective, may not require interaction or use of the target language to complete (Carless, 2004).

Another drawback associated with TBLT is that it may be difficult to implement in differing teaching contexts (Ellis, 2009). TBLT appears to be an approach that works well with students who are willing to take risks in their learning (Hyland, 2006), but may not be preferred by students who are familiar with more traditional approaches that involve direct grammar teaching and a structured curriculum (Mann, 2006). In the Canadian context, Ogilvie and Dunn (2010) have pointed out that new teachers entering the profession perceive a "need to adhere to cultural norms and expectations related to teaching" (p. 172). These cultural norms and expectations are not particularly supportive of a task-based language teaching approach. Although preservice teachers might feel positively disposed toward TBLT because of their teacher education experiences, they are not likely to use TBLT during a teaching practicum, perhaps because of a perceived lack of support for student teachers wanting to use TBLT. In addition, for Ogilvie and Dunn, it appears that preservice teachers may be reticent to employ TBLT because it does not contribute to promoting their status as language experts in the eyes of their students. Even when a teaching context is amenable to TBLT, there remains the perception amongst preservice teachers that TBLT involves timeconsuming preparations; as a result, Ogilvie and Dunn found that perceived time constraints placed on preservice teacher candidates limited their use of TBLT activities.

Misunderstandings and misconceptions surrounding TBLT have also been reported in the literature (Ellis, 2009). The variety of definitions of task - that is, what is or is not a task, and what activities it does or does not include-creates a feeling of uncertainty in teachers. This may be another reason why teachers are skeptical about TBLT and whether or not their students are actually progressing in their language abilities. Plews and Zhao (2010) point out that these misunderstandings and misconceptions persist in the Canadian context as well, with teachers struggling with TBLT and using what they perceive to be TBLT in ways that may be inconsistent with actual TBLT principles. For example, Plews and Zhao reveal in their study that teachers from native English-speaking backgrounds were apt to transform TBLT into a Present, Practice, and Produce (PPP) mode of instruction. Thus, lessons became driven by a weak form of TBLT fronted by explicit grammar explanations followed by drills and practice resembling traditional teaching practices rather than the task sequence of the strong form of TBLT. In addition, there was a tendency to separate the four skills of reading, writing, 
listening, and speaking as the focus of lessons rather than integrate the four skills in a whole language approach more consistent with a TBLT theoretical foundation.

Assessment is another concern in TBLT. Pica (2008) says "the label 'task' is applied to measures of L2 proficiency that are essentially communicative activities rather than tasks, which have a goal outside of language" (p. 78). The doing of the task puts the students in an environment where linguistic and communicative demands are put on them, but these may not be part of the task. This is confusing for the teacher who does not know what or how to assess students. Norris, Brown, Hudson, and Yoshioka (1998) argue that "success or failure in the outcome of the task, because they are performances, must usually be rated by qualified judges" (as cited in Nunan, 2004, p. 145). Similar to Pica, Norris et al. (as cited in Nunan, 2004) reinforce that tasks need to be authentic and include a goal. The concern, however, may be that language teachers do not consider themselves experts in the fields their students will be studying post-EAP, and they do not have the confidence to assess discipline-specific tasks outside their range of expertise. Furthermore, the language that students need to perform the task, such as that used in negotiating or describing a process or specific language related to the task, may be unfamiliar to the teacher, thus further contributing to a lack of confidence connected to assessing task performance in academic fields of study other than that connected to teachers' educational backgrounds.

\section{The Study}

\section{Participants}

Participants were recruited from the membership of the Teachers of English as a Second Language Canada Federation (TESL Canada). TESL Canada is a national federation of provincial and territorial organizations of English as an Additional Language (EAL) professionals. Member affiliates include organizations in British Columbia, Alberta, Saskatchewan, Manitoba, Ontario, New Brunswick, Prince Edward Island, Nova Scotia, and Yukon. As an umbrella organization, TESL Canada aims to promote high quality additional language teaching and learning in concert with its member organizations (TESL Canada, 2013). The current study focuses on participants who identified themselves as uniquely being EAP instructors. EAP instructors typically teach in programs existing in a variety of institutions in the Canadian context such as private adult ESL schools, colleges, and universities. In general, EAP involves "teaching English with the aim of facilitating learners' study or research in that language" (Hyland \& Hamp-Lyons, 2002, p. 2). Other instructors were not included in the current pool of data. These data covering a wider range of instructor specializations are reported elsewhere (Douglas, 2014). 


\section{Data Collection}

Data collection was carried out through an online survey of the TESL Canada membership. At the time of the study (Spring/Summer 2013), total membership in TESL Canada was 6,833. After the appropriate ethics board approvals were received and the protocols of TESL Canada and TESL Ontario were met, an e-mail invitation was sent out to the TESL Canada membership to take part in the survey. A total of 217 members answered the call to participate, representing $3.18 \%$ of the TESL Canada membership. Out of this larger pool of data, 42 participants indicated that they were working strictly within an EAP context at the time of the survey. It is these 42 participants who are the focus of the current study.

The online survey first presented participants with Ellis's (2009) definition of task in which he summarized it as having a focus on communicating and understanding meaning, requiring an information gap, depending on students' own language resources, and targeting a final goal other than language practice. Participants were asked to keep Ellis's (2009) definition in mind as they worked through the questions in the survey.

There were 11 questions on the survey. Questions 1-7 were closed-ended and Questions 8-11 were open ended. The first four questions of the survey collected demographic data connected to education, teaching contexts, location, and years of experience of the participants. The fifth question was a priming question designed to connect the Ellis (2009) definition of TBLT to concrete examples of tasks: from a list of seven choices, participants were asked to choose which task descriptions were representative of TBLT. The sixth and seventh questions inquired as to the frequency with which participants employed TBLT approaches in their teaching practice along with the extent to which they felt that TBLT activities were appropriate for EAP. The final four open-ended questions elicited participant responses related to examples of successful TBLT, the benefits of TBLT, the drawbacks of TBLT, and other thoughts related to TBLT.

\section{Data Analysis}

Qualitative research methods, influenced by a phenomenological tradition, were employed to categorize and code the data into emergent themes based on arising patterns (Creswell, 1998; Gay, Mills, \& Airasian, 2012). The goal of the research was to uncover participants" "lived experiences" (Creswell, 1998, p. 51) and perceptions in connection to the phenomenon of TBLT while capturing participant descriptions of TBLT in practice. Although the study was grounded in Ellis's (2009) definition of task, the data were approached inductively without preconceived thematic categories in order to directly uncover meaning in the data from the perspectives of the participants. The themes that arose were particularly grounded in the responses of the participants. For the open-ended questions, participant responses 
were analyzed for units of meaning. Units of meaning are ideas that can be gathered together to form groups of thoughts connected to a similar theme (Creswell, 1998). They are the informational building blocks in the data from which the thematic understandings are derived. As a result, some responses from participants were coded for more than one theme, with multiple codes assigned to responses conveying more than one separate idea in a response. Each separate idea, represented by a code, signifies a discrete unit of meaning that stood on its own as a unit of analysis. Coded units of meaning were grouped into thematic categories that became the basis for understanding participant perspectives on TBLT (Gay et al., 2012). In reporting the data, representative quotes were used to illustrate the emergent themes. A composite approach was taken (Plews \& Zhao, 2010), mixing the responses of the participants to capture the essence of the phenomenon under investigation: TBLT in the Canadian EAP context. It is important to note that as EAP instructors, researchers, and scholars, we attempted to remain aware of our particular interpretive focus and bias during the data analysis. We maintained this awareness so as to avoid premature judgement of the emerging themes in the data (Gay et al., 2012).

\section{Results}

\section{Demographic Information}

The first four questions of the survey provided data describing participant characteristics. Data results showed participants holding a variety of qualifications preparing them for teaching EAP: $60 \%$ of respondents reported holding a bachelor's degree, and a further $57 \%$ reported holding a master's degree. However, no specification was made as to whether these qualifications were focused on EAP or additional language teaching and learning in general. Participants' educational qualifications are summarized in Table 1.

Table 1

Educational Qualifications ( $n=42)$

\begin{tabular}{lcc}
\hline Response & Percentage & Count \\
\hline Doctoral degree & 12 & 5 \\
Master's degree & 57 & 24 \\
Diploma & 7 & 3 \\
Certificate ( $\geq 120$ hours) & 38 & 16 \\
Certificate $(<120$ hours) & 14 & 6 \\
Bachelor's degree & 60 & 25 \\
Other, please specify & 5 & 2 \\
\hline
\end{tabular}

Of the 217 respondents to the larger survey, 42 participants uniquely identified as working in an EAP context. These 42 participants are the focus of 
this study. Participants from six provinces took part in the survey (along with three participants from overseas). Half of the respondents were from Ontario, with British Columbia and Alberta following with $17 \%$ and $12 \%$ of respondents respectively. Table 2 summarizes the locations of participants' teaching practice.

Table 2

Locations of Teaching Practice $(n=42)$

\begin{tabular}{lcc}
\hline Response & Percentage & Count \\
\hline Nova Scotia & 2 & 1 \\
Prince Edward Island & 5 & 2 \\
Ontario & 50 & 21 \\
Manitoba & 7 & 3 \\
Alberta & 12 & 5 \\
British Columbia & 17 & 7 \\
Outside Canada & 7 & 3 \\
\hline
\end{tabular}

Finally, the demographic data results revealed that participants had an average of almost 16 years of experience teaching $\operatorname{EAP}(n=42, M=15.6, S D=$ 9.1 , range $=2-35$ ).

\section{Priming, Prevalence, and Suitability}

In considering which activities represented TBLT tasks, participants were asked to select all the activities that they felt represented TBLT. Results revealed that participants considered making a presentation as most representative of a TBLT approach, with $81 \%$ of participants considering this choice a task. The least representative of a TBLT task was reviewing test-taking strategies; however, this was still considered to be a task by $33 \%$ of the respondents. Results for the priming question are summarized in Table 3.

Table 3

Representative of TBLT Tasks $(n=42)$

\begin{tabular}{lcc}
\hline Response & Percentage & Count \\
\hline Reviewing test-taking strategies & 33 & 14 \\
Planning a class potluck party & 74 & 31 \\
Giving directions & 76 & 32 \\
Giving a presentation & 81 & 34 \\
Making a YouTube video & 79 & 33 \\
Writing a timed essay & 50 & 21 \\
Revising an essay after receiving feedback & 48 & 20 \\
\hline
\end{tabular}


The data reveal that TBLT is widely prevalent in participants' teaching practice, with $69 \%$ of the participants reporting that they used TBLT activities with their students in more than half of their lessons. Only one participant reported never using TBLT activities. The prevalence of TBLT activities in participant classrooms is summarized in Table 4.

Table 4

Prevalence of TBLT in Participants' Teaching Practice $(n=42)$

\begin{tabular}{lcc}
\hline Response & Percentage & Count \\
\hline Never & 2 & 1 \\
In the occasional lesson (approximately 25\%) & 26 & 11 \\
In about half of my lessons (approximately 50\%) & 24 & 10 \\
In the majority of my lessons (approximately 75\%) & 26 & 11 \\
In all of my lessons (approximately 100\%) & 19 & 8 \\
Other, please specify & 2 & 1 \\
\hline
\end{tabular}

Regarding the suitability of TBLT for specifically EAP contexts, $86 \%$ of participants felt that TBLT activities are appropriate for teaching EAP. However, that left $14 \%$ of respondents feeling either neutral or negative about the suitability of TBLT for EAP instruction. Results are summarized in Table 5.

Table 5

Perceived Suitability of TBLT for EAP Instruction $(n=42)$

\begin{tabular}{lccccc}
\hline & $\begin{array}{c}\text { Strongly } \\
\text { disagree }\end{array}$ & Disagree & Neutral & Agree & $\begin{array}{c}\text { Strongly } \\
\text { agree }\end{array}$ \\
\hline $\begin{array}{l}\text { Task-based language } \\
\text { teaching activities are } \\
\text { appropriate for teaching }\end{array}$ & $3(7 \%)$ & $1(2 \%)$ & $2(5 \%)$ & $18(43 \%)$ & $18(43 \%)$ \\
$\begin{array}{l}\text { English for Academic } \\
\text { Purposes }\end{array}$ & & & & & \\
\hline
\end{tabular}

\section{Examples of Successful TBLT Tasks in EAP}

Of the 42 participants who identified themselves as working within an EAP context, 32 provided responses to the question asking for examples of typical TBLT activities they had used in their current teaching context. Data provided by the 32 respondents resulted in 42 examples of TBLT outcomes. The most common examples provided by participants were presentations, essays, and interviews. Response results are summarized in Table 6. 
Table 6

Reported Examples of Typical TBLT Activities $(n=32)$

\begin{tabular}{lcc}
\hline Code & Number & Percentage \\
\hline Presentation & 15 & 35.7 \\
Essay & 8 & 19.0 \\
Interview & 3 & 7.1 \\
Timed reading & 2 & 4.8 \\
Video & 2 & 4.8 \\
Outline & 2 & 4.8 \\
Cover letter & 1 & 2.4 \\
Crossword & 1 & 2.4 \\
Debate & 1 & 2.4 \\
Instructions & 1 & 2.4 \\
Paraphrase & 1 & 2.4 \\
Project & 1 & 2.4 \\
Role-play & 1 & 2.4 \\
Riddle & 1 & 2.4 \\
Summary & 1 & 2.4 \\
Questionnaire & 1 & 2.4 \\
Total units of meaning & 42 & 100.0 \\
\hline
\end{tabular}

Making up almost $36 \%$ of the coded data, the most common example of a TBLT activity reported by participants mentioned presentations. These responses focused on "developing presentation skills" and "preparing for a presentation," with some examples connected to students' academic needs and "the field of their future disciplines." Representative of the examples, one instructor described a presentation task as follows:

We recently read an article comparing Bilingual Education language programs to ESL immersion programs in the USA. They [students] were then asked to give a group Powerpoint presentation discussing the pros and cons of each in their opinion.

After presentations, essays were the next most described TBLT example in the data, representing $19 \%$ of the coded data. The connection to academics was emphasized in the data, with students encouraged to "write with purpose based on their own academic background." One respondent also emphasized that "in an EAP context, writing an essay is an authentic task." The same respondent described a complex essay task involving multiple steps:

Students read articles/textbook chapters and listen to lectures in the fields of sociology and psychology, read a novel (I Heard the Owl Call My Name), and then for their final research paper, they have to synthesize the information from their readings and other research that they undertake, to write a commentary on some aspect of the novel. 
The third most popular TBLT example-interviews-was described in approximately $7 \%$ of the data. Interviews seemed to primarily serve an information-gathering role supporting either an essay or a presentation. For example, EAP students might be asked to interview a local business person in a neighbourhood to provide content for a presentation. Interviews might also be connected to students' future fields of study or career paths, with one example asking students to "find someone in the community to conduct an informational interview with regards to a career that you are interested in exploring following your studies in EAP."

\section{Benefits of TBLT in EAP}

For the open-ended question asking participants to share the possible benefits of employing TBLT activities in their current teaching context, 37 responses resulted in 67 coded units of meaning. The most reported benefits of TBLT were its practicality, effectiveness, and learner-centredness. The results are summarized in Table 7.

Table 7

Perceived Benefits of TBLT for EAP $(n=37)$

\begin{tabular}{lcc}
\hline Code & Number & Percentage \\
\hline Practicality & 15 & 22.4 \\
Effectiveness & 9 & 13.4 \\
Learner centred & 8 & 11.9 \\
Authenticity & 7 & 10.4 \\
Goal oriented & 6 & 9.0 \\
Motivation & 6 & 9.0 \\
Collaboration & 5 & 7.5 \\
Integration & 5 & 7.5 \\
Cognitive skills & 2 & 3.0 \\
Confidence & 2 & 3.0 \\
Creativity & 2 & 3.0 \\
Total units of meaning & 67 & 100.0 \\
\hline
\end{tabular}

Practicality, the most reported benefit in the data, accounted for approximately $22 \%$ of coded units of meaning in the responses. Practicality was related to how relevant TBLT activities are to the needs of EAP students and how these activities can prepare "the students for similar tasks in their future degree courses." For example, one participant reported that TBLT

can allow students to complete practical tasks that may be necessary in a university/college setting (i.e., working with community, groups, colleagues, etc., conducting interviews for studies/research).

TBLT is also seen as effective in EAP instruction, as 13\% of responses mentioned that as a perceived benefit of TBLT. Participants report that "students 
feel a sense of achievement and progress" and a "sense of accomplishment regardless of their level." They felt that TBLT activities "are more effective than other methods of teaching. Students learn and retain more information and are able to [use] skills taught more effectively over the long term."

Rounding out the top three benefits of TBLT as perceived by the study participants is the learner-centredness of this approach, mentioned in $12 \%$ of the responses. The participants felt that having a learner-centred classroom is appropriate, and TBLT helps to facilitate that because "activities are more student-centred; therefore, the teacher is a facilitator instead of the main focus. Students need to learn and get information from each other." Furthermore, "more student involvement (task-based activities) allows for more learning commitment and ownership on the students' part."

\section{Drawbacks of TBLT in EAP}

In addition to eliciting participants' opinions on the benefits of TBLT as a teaching approach for EAP, participants also had the opportunity to share the perceived drawbacks of using TBLT in EAP. In total, 34 participants reported drawbacks associated with using TBLT in EAP contexts. The 34 responses included 48 drawbacks that were coded in the data. The most prevalent drawbacks reported were a mismatch with student expectations, a lack of classroom time, and excessive instructor preparation. Reported drawbacks are summarized in Table 8.

Table 8

Perceived Drawbacks of TBLT for EAP $(n=34)$

\begin{tabular}{lcc}
\hline Code & Number & Percentage \\
\hline Student expectations & 11 & 22.9 \\
Classroom time & 9 & 18.8 \\
Instructor preparation & 7 & 14.6 \\
Curriculum mismatch & 6 & 12.5 \\
Focus on form & 4 & 8.3 \\
Instructor willingness & 4 & 8.3 \\
None & 4 & 8.3 \\
Evaluation & 3 & 6.3 \\
Total units of meaning & 48 & 100.0 \\
\hline
\end{tabular}

The most commonly perceived drawback from the point of view of the study participants, representing $23 \%$ of the data, was connected to student expectations for teaching and learning in an EAP class and how these expectations were not necessarily amenable to TBLT, resulting in resistance to TBLT methodologies. Part of this resistance to TBLT was attributed to cultural reasons, as illustrated in the statement that "cultural background may pose a challenge: some students are not very fond of learner-centred tasks and may be expecting the instructor to do all the teaching." Students are perceived as 
being "often unfamiliar with these kinds of projects," and this can result in "student push-back to be expected if they are used to more traditional teaching methods." For example, "students who are traditional 'book learners' don't always see the learning that is involved with TBL[T]," and "some students always want the correct answer and [do] not want to learn from fellow classmates." As a result, "it takes some 'selling' to students who would rather be taught grammar in a more traditional mode."

Challenges related to classroom time and instructor preparation also formed a recurring pattern in the data. While some students may resist TBLT, some instructors shared the opinion that TBLT is overly time-consuming in an EAP context (19\% of the drawbacks mentioned). As one participant lamented, "I don't always have the time I need for these activities." TBLT is perceived as being "time-intensive, using more class time than some other methods," and too "time-consuming in a fast-track program." TBLT was also perceived as being time-consuming and challenging in terms of instructor preparation, with $15 \%$ of the data associated with this drawback. It was reported that TBLT "requires more instructor preparation" with "careful planning ... and skillful implementation." As a result, "instructors have to be quite skilled in designing assessments" because TBLT is "difficult to organize."

\section{Further Thoughts on TBLT in EAP}

The last open-ended question in the online survey gave participants the opportunity to share any final thoughts they had about TBLT and teaching in an EAP context. Nearly half (19) of the participants availed themselves of this opportunity, with the four most common final thoughts being connected to TBLT's effectiveness, time consumption, ambiguous definition, and mismatch with student expectations. Results are summarized in Table 9.

Table 9

Further Thoughts Connected to TBLT and EAP $(n=19)$

\begin{tabular}{lcc}
\hline Code & Number & Percentage \\
\hline Effectiveness & 10 & 32.3 \\
Time-consuming & 4 & 12.9 \\
Definition & 3 & 9.7 \\
Student expectations & 3 & 9.7 \\
Importance & 2 & 6.5 \\
Goal oriented & 2 & 6.5 \\
Authenticity & 1 & 3.2 \\
Complementary & 1 & 3.2 \\
Further examples & 1 & 3.2 \\
Curriculum mismatch & 1 & 3.2 \\
Focus on form & 1 & 3.2 \\
Learner centred & 1 & 3.2 \\
Motivation & 1 & 3.2 \\
Total units of meaning & 31 & 100.0 \\
\hline
\end{tabular}


One theme that was prevalent in the replies of respondents (found in 32\% of the data) was TBLT's effectiveness for supporting language acquisition. One participant, when describing an example of a task, stated that "the result of this task over the past years has been very positive for me," with another participant emphasizing that "students feel a great sense of accomplishment." Thinking about TBLT activities, some participants said they "love them and use them all the time," and one respondent confirmed this thought by stating "I am a big fan of task-based learning." There appeared to be a general feeling that TBLT was "well worth the effort" and a "rewarding experience."

Another thought that echoed through the statements about drawbacks connected to TBLT was the time-consuming nature of this type of approach. Nearly one third (31\%) of the units of meaning coded for added thoughts contributed to this theme. One participant reported, "I am concerned about the time requirements," and another respondent emphasized "I always wish I had more time!" Yet, despite the concern with the perceived time consumption of employing a TBLT approach, a participant expressed the feeling that "it is worth the time investment by the instructor-especially when accompanied by the smile of understanding and success on the students' faces."

Rounding off the top four themes emerging in the data connected to added thoughts, the definition of TBLT $(10 \%)$ and student expectations $(10 \%)$ represented an equal number of units of meaning. There seemed to be some confusion as to what constitutes TBLT, as one participant noted that it was "difficult to determine which activities are tasks," and another worried that he or she may "have defined it [TBLT] so broadly that 'task-based learning' ... may not be that useful a concept." One participant also reported that he or she was now questioning his or her own understanding of TBLT after completing the online survey:

Before doing this, I thought I knew what task-based learning was, but the more I write, the more I realize I'm not $100 \%$ sure ... Hmmmm. I guess it's easier to define in a survival-based LINC or ESL class.

Along with ambiguity surrounding participants' understanding of TBLT, the theme of mismatched student expectations arose again in the data. One participant commented, "You [instructors] have to weather a lot of anxiety and complaining and griping, and you have to be very clear on what they [students] are learning from this, and why you are doing it this way." The feeling also recurred that "some students want fill in the blank or workbook type language activities because they provide right and wrong answers."

\section{Discussion}

The main goal of this study was to investigate, from the point of view of EAP practitioners in the Canadian context, the prevalence and perceived suitabil- 
ity of TBLT in EAP classrooms, examples of successful TBLT activities, and how EAP instructors perceived the benefits and drawbacks of TBLT.

For the participants in this study, TBLT is prevalent in their practice and generally regarded as appropriate for EAP instruction $-69 \%$ of the participants reported that they use TBLT activities in their EAP teaching, and 86\% reported that TBLT is suitable for teaching EAP. These data point to the acceptance of TBLT by the participants working in EAP contexts. These data also somewhat mitigate concerns in the data that TBLT may not fit with student expectations, may be time-consuming, or may entail excessive preparationdespite these concerns, a majority of the participants were employing TBLT methodologies with their learners. However, some respondents reported using TBLT activities only occasionally, and $14 \%$ felt neutral or negative about the suitability of TBLT. One reason may be related to curriculum or programmatic constraints, as voiced by participants who reported that their "current curriculum does not support it" and "a lot of our curriculum doesn't lend itself well to task-based learning." Ellis (2009) points out that TBLT may be difficult to implement in particular teaching contexts, perhaps similar to those of the participants. These findings suggest that the participants may not be given the freedom to choose what their courses will include or that their course syllabus is handed to them by administration. Despite perceptions to the contrary, the Canadian context continues to have cultural norms and expectations that may not foster a receptive environment for TBLT (Ogilvie \& Dunn, 2010).

The majority of examples of typical TBLT activities reported in the survey are productive in that they practice speaking or writing (e.g., cover letter, debate, role-play). The three most common activities were presentations, essays, and interviews. The comments suggest that participants value student interaction and activity in their classes as well as spoken and textual output. It is important to note that Willis and Willis (2007) point out taskbased language classes are not typically limited to using single stand-alone tasks. Rather, they use a sequence of interconnected tasks, employing all four language skills (reading, writing, listening, speaking) over the course of the sequence. This sequence is preceded by introductory priming tasks and followed by focus on form tasks. As a result, this task cycle can allow for attention to be placed on listening and reading, which was not mentioned by the participants when reporting examples of TBLT in EAP. The focus on productive tasks uncovered in the data could have been a result of participants focusing on reporting only one element of a sequence of tasks. It may have also been the result of inconsistencies between TBLT principles and practice in EAP practice similar to the inconsistencies reported by Plews and Zhao (2010) in the general ESL context. However, some of the descriptions of examples were extensive and detailed, involving the integration of the four skills and including several subtasks making up a complete sequence of tasks. An example in the survey is "students look at case studies from 
the field of their future disciplines, write up different perspectives, and present." This integration of different language skills such as reading and writing connects to participants reporting the benefits of integration as an aspect of TBLT. Students "interviewing" people in the community or each other in class was another reported TBLT activity. This example of a task is mirrored in a comprehensive list of study skills in the literature (Jordan, 1997) as a study skill for doing research, pointing to a connection with EAP. Interviews allow students to interact with people in the community or on campus, which not only provides learners with authentic experiences, but also develops their conversation skills. As a whole, the examples of TBLT in practice reported by the participants complement the perceived benefits of using this approach.

The most reported benefits of TBLT were its practicality, effectiveness, and learner-centredness. The reported benefits of TBLT presumably reflect values held by the respondents. These benefits in the data are similar to the benefits of other approaches and methods such as communicative language teaching, cooperative learning, and content-based instruction (Brown, 2007). Many of the benefits found in the data are not exclusive features of TBLT, but widely accepted principles of language teaching and learning (Brown, 2007). It is possible that many of the participants would have been exposed to these ideas in their initial teacher education programs or ongoing professional development activities. It may be that participants are applying general positive attributes surrounding good teaching to TBLT. Unsurprisingly, the participants regard the positive benefits of TBLT as key principles, along with others - such as motivation and student confidence-as essential for language learning. Furthermore, the participants mention the benefits of "real-world" and "authentic" tasks, that is, tasks students have to know how to perform during and after their postsecondary studies. Comments in the data suggest that the participants feel that their students are not merely learning English for its own sake, but because they need to use English in their postsecondary lives. The importance of authentic contexts, materials, and student communication to stimulate language and skill development is found throughout the survey as well as in the literature (Ellis, 2003b; Nunan, 2004).

Participants felt that a mismatch with student expectations, lack of classroom time, and excessive instructor preparation were common drawbacks of using TBLT for teaching EAP. In particular, it was suggested in the responses that some of the participants' students have a background in more "traditional classrooms" where the teacher is dominant and the students are passive and do not have control over the content. The implication is that these students would not be amenable to TBLT approaches. These comments are supported by Mann's (2006) assertion that TBLT may not be appreciated by students who have been taught using traditional approaches involving direct grammar instruction and a structured curriculum. How- 
ever, despite the report of possible resistance to TBLT-style methodologies, there is a sense in the data that the participants are sensitive to their students' learning styles, try to build a relationship of trust in the classroom, and strive to create a positive atmosphere. This sense of TBLT being worth the effort is seen in an expanded representative quote, previously used to illustrate mismatched student expectations, in which a participant emphasizes success despite the challenges:

Students feel a great sense of accomplishment, but you [instructors] have to weather a lot of anxiety and complaining and griping, and you have to be very clear on what they are learning from this, and why you are doing it this way.

Furthermore, statements such as "convincing students" and obtaining "student buy in" suggest that participants are willing to negotiate class content and make the benefits of TBLT explicit for their students, which is connected to learner-centredness.

Survey results also seem to support the notion that while TBLT is seen by participants as a valid approach in an EAP setting, misconceptions remain as to what actually constitutes TBLT. The comments about the uncertainty of the meaning of "task" and "task-based learning" are consistent with what is written in the literature; that the lack of a single definition of "task" creates confusion (Ellis, 2009). Furthermore, similar to findings by Ogilvie and Dunn (2010) connected to the perceived time constraints surrounding TBLT, challenges related to classroom time and instructor preparation were a recurring pattern in the data. Comments such as "time has to be shared between providing course content and activities," "there is often too much emphasis on the timing of the task," and "task-based learning doesn't always spend enough time building students' knowledge of linguistic structures" support the misconceptions surrounding TBLT and how this approach can support curricular goals. With greater understanding of what constitutes TBLT, it is possible that there would be more acceptance of this approach in a wider variety of curricular contexts.

\section{Conclusion}

Although the current study provides an interesting picture of TLBT in practice in EAP contexts across Canada, there are a number of limitations to the current study. First, because participants were recruited through e-mail, the topic of TBLT may have attracted participants with strong feelings connected to this topic. For example, proponents of TBLT may be overrepresented in the data because they wanted to share their knowledge and expertise on the subject. Another point that limits the generalizability of the data is the small sample size compared to the likely number of EAP teachers in Canada and the total size of the TESL Canada membership in general. Furthermore, as 
Quebec's provincial organization representing English-language teachers is not a member of TESL Canada, we had no participants from this province. Despite these limitations, informative patterns connected to TBLT and its relationship with EAP do arise in the data. These patterns call for further investigations into TBLT and EAP. For example, results suggest that it would be productive to do a larger, more detailed study to find out how teachers are actually incorporating TBLT into their EAP teaching and what effects this approach is having on the language and skill development of their students. The results of such a study would have an impact on course development and curriculum design. The current study also points to how it would be beneficial to see further research to understand the role of the teacher and the role of tasks in helping EAP students prepare for university. Finally, future research capturing EAP student voices to understand their perceptions of TBLT in Canadian EAP contexts would complement the teacher perspectives reported in the current study.

There is a sense in the data received that the participants perceive TBLT as a suitable approach for teaching EAP because their students learn language and skills in natural contexts and situations. By working toward a goal, students use necessary language, making learning more authentic and relevant. TBLT motivates EAP students to improve their language and skills. However, comments with the opposite view that arose in the data suggest that more support for implementing TBLT approaches in an EAP context are called for. This support could take the form of designing EAP materials, such as textbooks, to incorporate TBLT principles for teaching and learning. More such materials would help to lower the preparation demands placed on instructors looking to make TBLT part of their EAP practice. The increased availability of TBLT-informed EAP materials could also be accompanied by greater attention to what TBLT in the EAP classroom constitutes in order to further promote TBLT in EAP teacher education and professional development opportunities.

\section{Acknowledgements}

The authors extend thanks to the editors of the TESL Canada Journal and the anonymous reviewers for their helpful suggestions and comments on an earlier draft of this article.

\section{The Authors}

Scott Roy Douglas is an assistant professor in the Faculty of Education at the University of British Columbia's Okanagan campus. His current research interests include vocabulary and large-scale English language testing, novice academic writing, and English for Academic Purposes curriculum and materials design.

Marcia Kim is an instructor in the English for Academic Purposes program at the University of Calgary. Her current research interests include ESL methodology, teacher training, and English for Academic Purposes. 


\section{References}

Alexander, O., Argent, S., \& Spencer, J. (2008). EAP essentials. Reading, UK: Garnet.

Baik, C., \& Greig, J. (2009). Improving the academic outcomes of undergraduate ESL students: The case for discipline-based academic skills programs. Higher Education Research and Development, 28(4), 401-416.

Brown, H. D. (2007). Teaching by principles: An interactive approach to language pedagogy (3rd ed.). White Plains, NY: Pearson Education.

Carless, D. (2004). Issues in teachers' reinterpretation of a task-based innovation in primary schools. TESOL Quarterly, 38(4), 639-662.

Citizenship and Immigration Canada. (2013, February 26). Canada welcomes record number of international students in 2012. Retrieved from http://news.gc.ca/web/article-en. do?nid=722709

Counsell, J. (2011). How effectively and consistently do international postgraduate students apply the writing strategies they have been taught in a generic skills-based course to their subsequent discipline-based studies? Journal of Academic Language and Learning, 5(1), 1-17.

Creswell, J. W. (1998). Qualitative inquiry and research design: Choosing among five traditions. Thousand Oaks, CA: Sage.

Douglas, S. (2014, May). Teacher perceptions of task-based language teaching and learning across Canada. Contact: Special Research Symposium Issue, 40(2), 11-31. Retrieved from http:// www.teslontario.net/publication/research-symposium

Ellis, R. (2003a). Designing a task-based syllabus. RELC Journal, 34(1), 64-81.

Ellis, R. (2003b). Task-based language learning and teaching. Oxford, UK: Oxford University Press.

Ellis, R. (2009). Task-based language teaching: Sorting out the misunderstandings. International Journal of Applied Linguistics, 19(3), 221-246.

Gay, L. R., Mills, G. E., \& Airasian, P. W. (2012). Educational research: Competencies for analysis and applications (10th ed.). Boston, MA: Pearson.

Hyland, K. (2006). English for Academic Purposes: An advanced resource book. New York, NY: Routledge.

Hyland, K., \& Hamp-Lyons, L. (2002). EAP: Issues and directions. Journal of English for Academic Purposes, 1(1), 1-12.

Jeon, I., \& Hahn, J. (2006). Exploring EFL teachers' perceptions of task-based language teaching: A case study of Korean secondary school classroom practice. Asian EFL Journal, 8(1), 1-27.

Jordan, R. R. (1997). English for Academic Purposes: A guide and resource book for teachers. Cambridge, UK: Cambridge University Press.

Larsen-Freeman, D., \& Anderson, M. (2011). Techniques and principles in language teaching (3rd ed.). Oxford, UK: Oxford University Press.

Long, M. H., \& Crookes, G. (1992). Three approaches to task-based syllabus design. TESOL Quarterly, 26(1), 27-56.

Mann, G. (2006). A task-based approach to the development of the oral skills of international law students. Research in Post-Compulsory Education, 11(2), 217-234.

McDonough, K., \& Chaikitmongkol, W. (2007). Teachers' and learners' reactions to a task-based EFL course in Thailand. TESOL Quarterly, 41(1), 107-132.

Nunan, D. (2004). Task-based language teaching. Cambridge, UK: Cambridge University Press.

Ogilvie, G., \& Dunn, W. (2010). Taking teacher education to task: Exploring the role of teacher education in promoting the utilization of task-based language teaching. Language Teaching Research, 14(2), 161-181.

Pica, T. (2008). Task-based instruction. In N. Van Deusen-Scholl \& N. H. Hornberger (Eds.), Encyclopedia of language and education (2nd ed., Vol. 4, pp. 71-82). New York, NY: Springer Science+Business Media, LLC.

Plews, J. L., \& Zhao, K. (2010). Tinkering with tasks knows no bounds: ESL teachers' adaptations of task-based language teaching. TESL Canada Journal, 28(1), 41-59. 
Samuda, V., \& Bygate, M. (2008). Tasks in second language learning. New York, NY: Palgrave Macmillan.

Seedhouse, P. (1999). Task-based interaction. ELT Journal, 53(3), 149-156.

Skehan, P. (1996). A framework for the implementation of task-based instruction. Applied Linguistics, 17(1), 38-62.

TESL Canada. (2013). Mission and values. Retrieved from http://www.tesl.ca/about-us/missionand-values/

Van den Branden, K. (2012). Task-based language education. In A. Burns \& J. C. Richards (Eds.), The Cambridge guide to pedagogy and practice in second language teaching (pp. 132-139). Cambridge, UK: Cambridge University Press.

Willis, J. (1996). A framework for task-based learning. Harlow, UK: Addison Wesley Longman.

Willis, D., \& Willis, J. (2007). Doing task-based teaching. Oxford, UK: Oxford University Press. 